\title{
Clinical and angiographic outcome in patients with in-stent restenosis and repeat target lesion revascularisation in small coronary arteries
}

\author{
C M Gross, J Krämer, O Weingärtner, F Uhlich, R Dietz, J Waigand
}

\begin{abstract}
Objective-To evaluate the clinical and angiographic outcome in patients with in-stent restenosis in small coronary arteries and repeat target lesion revascularisation.

Design-Patients with in-stent restenosis in coronary arteries $\leqslant 2.85 \mathrm{~mm}$ were eligible for the study and underwent target lesion revascularisation. Clinical and angiographic variables were assessed during a six month follow up period.

Results-73 patients with 79 lesions were treated by percutaneous transluminal coronary angioplasty (47\%), excimer laser angioplasty $(25 \%)$, or restenting $(28 \%)$. The mean (SD) reference diameter before target lesion revascularisation was $2.12(0.5) \mathrm{mm}$. Procedural success was achieved in all cases, but $57 \%$ of the patients had restenosis after six months. The rate of further restenosis was higher with laser angioplasty $(78 \%)$ than with restenting (47\%) or balloon angioplasty alone $(49 \%, \mathrm{p}<0.05)$.

Conclusions-Treatment for in-stent restenosis in small coronary arteries is feasible and safe, with a second restenosis rate comparable to large coronary artery series. The strategy of target lesion revascularisation influences further in-stent restenosis, with an increased rate with laser angioplasty compared with restenting and repeat dilatation alone.

(Heart 2000;84:307-313)
\end{abstract}

Keywords: restenosis; coronary stent; small vessels; coronary artery disease

Coronary stent placement reduces restenosis rate compared with conventional balloon angioplasty and improves outcome in patients with coronary artery disease. However, even in selected patients, in-stent restenosis occurs in 20-30\%. ${ }^{12}$ Most reports have concerned target vessels of $\geqslant 3 \mathrm{~mm}$ in diameter, ${ }^{12}$ and have shown an influence of vessel size on clinical and angiographic outcome..$^{3-7}$ The inverse relation between decreased vessel size and increased restenosis rate is responsible for doubts about the superiority of stent implantation over balloon angioplasty in small coronary arteries. $^{348}$ These considerations also take account of the risk of acute or subacute stent thrombosis in small coronary arteries which had been shown in previous trials. ${ }^{9-13}$

Studies on treatment of in-stent restenosis have shown satisfactory immediate results but a relatively high restenosis rate after six months. ${ }^{14-22}$ Generally, the angiographic recurrence of restenosis has varied between $22 \%$ and $75 \%,{ }^{23}$ and most experience has been gained with conventional percutaneous transluminal coronary angioplasty (PTCA). Although the optimal treatment procedure is still under debate and some predictors of restenosis have been identified, all currently available immediate and long term data on treatment of in-stent restenosis have been focused on the larger coronary vessels. As stent deployment becomes more widespread, and as stents are used in increasingly small coronary arteries, it will be important to assess the efficacy of percutaneous transluminal treatment of in-stent restenosis and the clinical outcome of such procedures in these patients. Our purpose in this study was to undertake a prospective evaluation of the immediate and longer term (six month) follow up after repeat treatment of in-stent restenosis in small coronary arteries, and to determine predictors of restenosis in such patients.

\section{Methods}

PATIENTS

Between July 1996 and January 1998, 73 of 179 patients $(41 \%)$ fulfilled the study criteria of significant in-stent restenosis in small coronary arteries with a reference lumen diameter $\leqslant 2.85 \mathrm{~mm}$, measured by quantitative coronary angiography. All the procedures described were performed according to our institutional guidelines and with the patients' written informed consent.

The patients underwent successful target lesion revascularisation for 79 in-stent restenoses. All were scheduled for a six month clinical and angiographic follow up examination. The mean (SD) interval from initial stent implantation to repeat percutaneous treatment was 6.3 (2.7) months.

At the time of initial stent placement, all patients had undergone high pressure post-dilatation and all were on long term aspirin treatment $(100 \mathrm{mg} /$ day) and ticlopidine (250 mg twice a day for four weeks). At the discretion of the operator, stent implantation was performed with either slotted tube stents (Inflow, $\mathrm{n}=5$; Inflow Dynamics, Munich, Germany; Palmaz-Schatz, $\mathrm{n}=44$; Johnson and Johnson, Warren, New Jersey, USA) or multicellular stents (MultiLink, $\mathrm{n}=38$; Advanced Cardiovascular Systems, Santa Clara, California, USA; Sito, $\mathrm{n}=4$; Sitomed, 
Unterschleißheim, Germany). In a few cases modular (AVE-GFX, $\mathrm{n}=8$; Medtronic/AVE, Santa Rosa, California, USA; Micro, $\mathrm{n}=1$; Medtronic/AVE, Santa Rosa, California, USA) or monofilament stents (Crossflex, $\mathrm{n}=3$; Miami, Florida, USA; Wiktor, $\mathrm{n}=2$; Medtronik, Minneapolis, Minnesota, USA) were implanted. To deploy these stents we selected $2.5 \mathrm{~mm}$ balloon sizes for vessels smaller than $2.5 \mathrm{~mm}$, and $3.0 \mathrm{~mm}$ balloons for vessels $\geqslant 2.5 \mathrm{~mm}$. Conventional balloon angioplasty followed stent implantation. Lesion morphology was interpreted according to the American College of Cardiology/American Heart Association (ACC/AHA) classification. ${ }^{24}$

REPEAT TRANSLUMINAL PROCEDURES

In all patients, repeat transluminal intervention was performed because of $\geqslant 50 \%$ recurrent restenosis associated with silent ischaemia or typical angina pectoris, which was classified according to the Canadian Cardiovascular Society (CCS). Preferably most interventions were conventional PTCA. Excimer laser coronary angioplasty (Spectranetics/Advanced Interventional Systems) as an atheroablative technique was performed as previously described. ${ }^{25}$ In all cases, either a $1.4-1.7 \mathrm{~mm}$ concentric laser catheter or, for larger vessels, a $2.0 \mathrm{~mm}$ concentric catheter was used with saline flushing to ablate the neointimal tissue mass, followed by balloon angioplasty.

Additional stent deployment was used in cases of suboptimal dilatation or where there was intimal dissection after balloon angioplasty. All patients received heparin during the procedure, long term aspirin treatment, and ticlopidine for four weeks if a second stent was implanted.

ANGIOGRAPHIC ANALYSIS

A single operator, using the automated edge detection algorithm (CAAS II, PIE Medical System, Maastricht, Netherlands) for quantitative assessment, analysed all the cineangiograms blind. Quantitative analyses were performed for each lesion at baseline and at each follow up interval. After selection of two orthogonal projections, minimum lumen diameter, reference lumen diameter, lesion length, and diameter stenosis (\%) were measured. Intracoronary glyceryl trinitrate $(200 \mu \mathrm{g})$ was given before angiographic assessments. Acute gain, net gain, and late loss were calculated for each follow up interval. Angiographically detected dissections were classified according to the National Heart, Lung, and Blood Institute criteria.

PRIMARY SUCCESS

A procedure was considered to be successful if the residual lumen narrowing immediately after stent placement was visually estimated as $<30 \%$, and no major adverse coronary event (myocardial infarction, acute or subacute stent occlusion, need for coronary bypass or target lesion revascularisation) occurred.
STENT RESTENOSIS

In-stent restenosis was defined as $\geqslant 50 \%$ diameter reduction and was further classified as diffuse ( $>10 \mathrm{~mm}$ in length) or focal. To determine in-stent diameter restenosis rate, reoccluded vessels were not excluded by statistical analysis.

FOLLOW UP

All patients were scheduled for clinical examination, ECG, stress testing, and angiographic follow up. Periprocedural complications (for example, raised creatinine kinase, subacute stent thrombosis, $\mathrm{Q}$ wave or non-Q-wave myocardial infarction, or peripheral vessel complications) were recorded and all patients had at least one visit in the outpatient clinic during follow up. The angina status according to the CCS was classified at baseline and at each visit. Major cardiac events were defined as death, non-fatal myocardial infarction (creatinine kinase increased more than twofold above the normal range and relative cardiac isoform $>6 \%$ ), and need for target lesion or vessel revascularisation (coronary artery bypass surgery or PTCA). Acute or subacute stent thrombosis was defined as angiographically documented vessel occlusion at the treated site within 24 hours or two months after the procedure.

STATISTICAL ANALYSIS

Data are presented as mean (SD). Comparison of continuous data between groups was performed using the unpaired Student $t$ test. Differences between proportions were assessed by $\chi^{2}$ analysis. Predictive values influencing restenosis were evaluated by analysis of variance. A probability value of $p<0.05$ was considered significant.

\section{Results}

INITIAL STENT PLACEMENT PROCEDURE AND PATIENT CHARACTERISTICS

Clinical baseline data and lesion characteristics at initial stent placement and at each follow up period for all patients are outlined in tables 1 and 2. Most target lesion revascularisations were performed in men (85\%), and the mean (SD) age of all the patients was 63 (8) years. Twenty one patients were diabetic and most had one or more additional conventional risk factors for coronary artery disease (table 1). Twenty six patients had initial stent placement for severe angina (CCS class III and IV). Nine patients had a previous coronary artery bypass graft operation. Multivessel disease was present in $65 \%$ of all patients. One hundred and five stents were successfully deployed in 79 vessels, using a stent to lesion ratio of 1.3. Slotted tube and multicellular stents were preferentially implanted (in $47 \%$ and $40 \%$, respectively). In 34 lesions more than one stent or hybrid stents had to be placed (table 2). Balloon pressure for stent deployment was 14 (3) atm.

\section{LESION CHARACTERISTICS}

In $76 \%$ of patients a suboptimal result after predilatation, or restenosis after previous percutaneous transluminal coronary angioplasty, 
Table 1 Clinical characteristics of 73 patients with in-stent restenosis

\begin{tabular}{ll}
\hline Number of patients & \\
Age (years) (mean (SD)) & 73 \\
Men & $63(9)$ \\
Women & $62(85)$ \\
Hypertension & $11(15)$ \\
PAD & $24(33)$ \\
Diabetes mellitus & $10(14)$ \\
Hypercholesterolaemia & $21(29)$ \\
Smokers & $34(47)$ \\
Interval from stent implantation to TLR & $39(53)$ \\
(months) (mean (SD)) & $6.3(2.7)$ \\
Interval from TLR to follow up (months) & \\
(mean (SD)) & $6.2(1.8)$ \\
Number of diseased vessels & \\
One & \\
Two & $24(34)$ \\
Three & $28(38)$ \\
CCS angina class (stent implantation) & $21(28)$ \\
I & \\
II & $10(14)$ \\
III & $39(53)$ \\
IV & $16(22)$ \\
CCS angina class (first reintervention) & $8(11)$ \\
0 & $7(10)$ \\
I & $14(19)$ \\
II & $33(45)$ \\
III & $17(23)$ \\
IV & $2(3)$ \\
O & \\
I & $10(14)$ \\
II & $18(25)$ \\
III & $29(40)$ \\
Number of lesions & $10(14)$ \\
Vessel treated & $6(8)$ \\
LAD & 79 \\
LCX & \\
RCA & $45(57)$ \\
Left main & $11(14)$ \\
SVG & $20(25)$ \\
CABG before stent & $1(1.3)$ \\
Previous PTCA & $2(2.5)$ \\
\hline Vass (follow up) & $9(12)$ \\
& $22(28)$ \\
\hline
\end{tabular}

Values are $\mathrm{n}(\%)$ unless otherwise stated.

CABG, coronary artery bypass graft; CCS, Canadian Cardiovascular Society; ISR, in-stent restenosis; LAD, left anterior descending coronary artery; LCX, left circumflex coronary artery; PAD, peripheral artery disease; PTCA, percutaneous transluminal coronary angioplasty; RCA, right coronary artery; SVG saphenous vein graft; TLR, target lesion revascularisation.

was the indication for stent placement. In $8 \%$ of all treated patients, stent placement was used as an emergency intervention (bail out), and in $46 \%$ of patients stents were delivered into infarct related arteries (table 2). In most patients (96\%), complex lesions, classified as type B and $\mathrm{C}$, were treated.

REPEAT PERCUTANEOUS TRANSLUMINAL TARGET LESION REVASCULARISATION

The mean (SD) interval between target lesion revascularisation and initial stent placement was 6.3 (2.7) months. All these patients had significant in-stent restenosis or showed total vessel occlusion in the presence of angina pectoris or stress test ischaemia. Thirty one in-stent restenotic lesions had to be classified as diffuse, 38 showed focal restenosis, and 10 vessels were occluded. No patient had suffered Q wave or non-Q-wave infarction. In $47 \%$, in-stent restenosis was treated by conventional balloon angioplasty. The mean balloon to artery ratio was $1.15: 1$, using appropriate balloon sizes. In $25 \%$ of all cases, atheroablative excimer laser angioplasty followed by conventional balloon angioplasty was performed. Ten vessels were reoccluded and two lesions with diffuse in-stent restenosis showed subtotal
Table 2 Angiographic and procedural analysis

\begin{tabular}{ll}
\hline Type of stent & \\
Slotted tube & $49(47)$ \\
Multicellular & $42(40)$ \\
Modular & $9(9)$ \\
Monofilament & $5(4)$ \\
More than one stent per lesion & $24(30)$ \\
Hybrid stent placement & $10(9.5)$ \\
Inflation pressure (initial stenting) (atm) & $14.5(3.0)$ \\
(mean (SD)) & \\
Indication for initial stent & $13(16)$ \\
Occlusion & $60(76)$ \\
Elective & $6(8)$ \\
Bail out & $36(46)$ \\
Infarct related artery & \\
Type of stenosis & $3(4)$ \\
A & $61(77)$ \\
B1/B2B & $15(19)$ \\
C1/C2 & 1.08 \\
Lesion/patient & 105 \\
Stents & 1.3 \\
Stent/lesion & \\
Type of in-stent restenosis & $31(39)$ \\
Diffuse & $38(48)$ \\
Focal & $10(13)$ \\
Occlusion & \\
Type of treatment for restenosis & $20(25)$ \\
ELCA & $37(47)$ \\
PTCA & $19(24)$ \\
Stent & $3(4)$ \\
ELCA/stent & \\
\hline Values are (\%) & \\
\hline
\end{tabular}

Values are $\mathrm{n}(\%)$ unless otherwise stated.

ELCA, excimer laser coronary angioplasty.

stenosis at target lesion revascularisation. All could be recanalised by PTCA or excimer laser coronary angioplasty and PTCA $(\mathrm{n}=12)$. The balloon inflation pressure for sole or adjunctive percutaneous transluminal coronary angioplasty was 12 (3.5) atm. Technical success was achieved in all patients, but additional stent placement was necessary in 19. Three patients had excimer laser coronary angioplasty and stent placement as a combined procedure.

CLINICAL FOLLOW UP

Clinical follow up was obtained in all patients. The mean follow up period extended from initial stent placement to reangiography after target lesion revascularisation (12.6 (2.5) months). One acute stent thrombosis accompanied by non-Q wave infarction occurred after excimer laser coronary angioplasty followed by stent implantation, because of dissection (AHA/ACC class C). Another patient had stent thrombosis after repeat balloon angioplasty within two months.

There was a significant reduction of angina symptoms during follow up. The presence of severe angina (CCS class III to IV) decreased during follow up (33\% to $22 \%, p=0.02)$, with $79 \%$ of patients having symptoms only after significant stress exercise (class $0-$ II).

QUANTITATIVE ANGIOGRAPHY AND ANGIOGRAPHIC FOLLOW UP

Angiography was performed after initial stent placement and six months after target lesion revascularisation in all patients. The mean reference lumen diameter initially was 2.17 $(0.4) \mathrm{mm}$, and $2.2(0.5) \mathrm{mm}$ at the end of follow up. At baseline, the mean minimum lumen diameter increased from $0.59(0.4) \mathrm{mm}$ to 2.07 $(0.4) \mathrm{mm}$ after stent implantation and decreased again to $0.58(0.4) \mathrm{mm}$ after target lesion revascularisation. Postintervention, there was a significant decrease in minimum 
Table 3 Baseline, target lesion revascularisation (TLR), and postinterventional angiographic analysis of 79 in-stent restenoses

\begin{tabular}{llll}
\hline & Baseline & TLR & Follow up \\
\hline RLD (mm) & $2.17(0.4)$ & $2.12(0.5)$ & $2.20(0.5)$ \\
MLD (mm) & $0.59(0.4)$ & $0.60(0.4)$ & $1.02(0.7)$ \\
DS (\%) & $72.4(17.0)$ & $72.7(15.0)$ & $55.0(27.2)$ \\
Length of stenosis (mm) & $13.1(5.9)$ & $14.0(5.8)$ & $13.9(5.8)$ \\
RLD post (mm) & $2.52(0.4)$ & $2.31(0.5)$ & \\
MLD post (mm) & $2.10(0.4)$ & $1.77(0.4)$ & \\
DS post (\%) & $17.5(7.2)$ & $23.3(8.0)$ & \\
Acute gain (mm) & $1.5(0.4)$ & $1.2(0.5)$ & \\
Late loss (mm) & $1.5(0.5)$ & $0.74(0.75)$ & \\
\hline
\end{tabular}

Values are mean (SD)

DS, diameter stenosis; RLD, reference lumen diameter; MLD, minimum lumen diameter.

Table 4 Restenosis rate, acute and net gain, and late loss of 79 in-stent restenoses

Restenosis rate follow up in terms of strategy of

TLR (\%)

ELCA

PTCA

Stent

Acute gain in terms of strategy of TLR (mm)

ELCA

PTCA

Stent

Late loss in terms of strategy of TLR (mm)

ELCA

PTCA

Stent

Net gain $(\mathrm{mm})$

Net gain follow up (mm)

Net gain in terms of strategy of follow up (mm)

ELCA

PTCA

Stent

Values are mean (SD).

lumen diameter, resulting in a reduction in acute gain compared with the value at initial stent implantation (minimum lumen diameter $2.1(0.4) \mathrm{mm}$, acute gain $1.5(0.4) \mathrm{mm}$, versus $1.77(0.4) \mathrm{mm}$ and $1.2(0.5) \mathrm{mm}$, respectively, after revascularisation, $\mathrm{p}<0.05)$. When analysed by diameter stenosis, the baseline percentage of stenosis severity was $72.4(17) \%$; this fell to 17 (7)\% after initial stent placement, with an increase in target lesion revascularisation of $73(15) \%$.

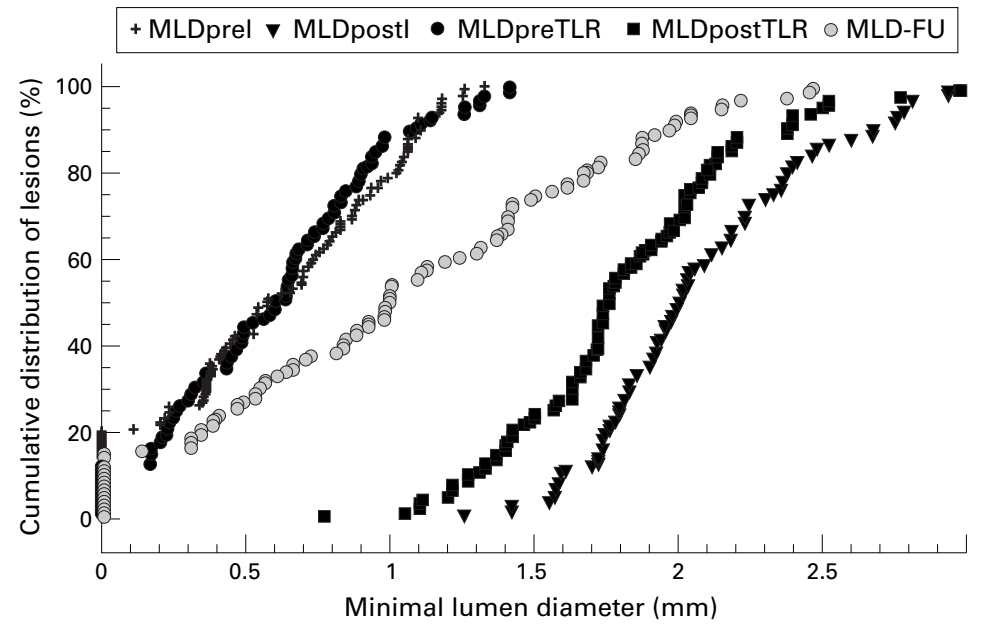

Figure 1 Cumulative frequency curves of minimum lumen diameter at baseline, immediately after stent implantation, before target lesion revascularisation (TLR), after TLR, and at follow up. MLDpreI, minimum lumen diameter before initial stent placement; MLDpostI, minimum lumen diameter after initial stent placement; MLDpreTLR, minimum lumen diameter before TLR; MLDpost TLR, minimum lumen diameter after TLR; MLD-FU, minimum lumen diameter at follow up.
Table 5 Univariate analysis of predictors for second in-stent restenosis in 79 lesions

\begin{tabular}{|c|c|c|c|}
\hline & $\begin{array}{l}\text { No } \\
\text { restenosis }\end{array}$ & Restenosis & $p$ Value \\
\hline \multicolumn{4}{|l|}{ Per patient } \\
\hline Age & & & NS \\
\hline$\leqslant 65$ years & $18(60)$ & $25(58)$ & \\
\hline$>65$ years & $12(40)$ & $18(42)$ & \\
\hline Men & $25(83)$ & $37(86)$ & NS \\
\hline Hypertension & $20(67)$ & $29(67)$ & NS \\
\hline Peripheral arterial disease & $3(10)$ & $7(16)$ & NS \\
\hline Diabetes mellitus & $6(20)$ & $15(35)$ & NS \\
\hline Hypercholesterolaemia & $14(48)$ & $20(46)$ & NS \\
\hline Smoking & $14(48)$ & $25(58)$ & NS \\
\hline \multicolumn{4}{|l|}{ Per lesion } \\
\hline $\begin{array}{l}\text { Strategy for in-stent } \\
\text { restenosis }\end{array}$ & & & 0.04 \\
\hline ELCA & 5 & 18 & \\
\hline PTCA & 19 & 18 & \\
\hline Stent & 10 & 9 & \\
\hline Previous PTCA & $19(63)$ & $32(74)$ & \\
\hline $\begin{array}{l}\text { Previous PTCA at treated } \\
\text { lesion }\end{array}$ & $11(37)$ & $11(26)$ & \\
\hline Stents per lesion & & & NS \\
\hline One & 25 & 30 & \\
\hline More than one & 9 & 15 & \\
\hline Hybrid stenting & 3 & 7 & \\
\hline Complex lesions (B/C) & $31(91)$ & $45(100)$ & NS \\
\hline Type of restenosis & & & NS \\
\hline Diffuse, occlusion & $16(47)$ & $25(56)$ & \\
\hline Focal & $18(53)$ & $38(44)$ & \\
\hline Infarct related artery & $19(56)$ & $17(38)$ & NS \\
\hline Indication for initial stent & & & NS \\
\hline Occlusion & $5(15)$ & $8(18)$ & \\
\hline Elective & $27(79)$ & $33(73)$ & \\
\hline Bail out & $2(6)$ & $4(9)$ & \\
\hline Type of stent & & & NS \\
\hline Slotted tube & 17 & 18 & \\
\hline Multicellular & 10 & 19 & \\
\hline $\begin{array}{l}\text { Severity of stenosis initial } \\
\text { stent }\end{array}$ & & & NS \\
\hline$<75 \%$ & $20(59)$ & $25(56)$ & \\
\hline$\geqslant 75 \%$ & $7(21)$ & $13(29)$ & \\
\hline $100 \%$ & $7(20)$ & $7(15)$ & \\
\hline $\begin{array}{l}\text { Severity of stenosis post } \\
\text { initial stent }\end{array}$ & & & NS \\
\hline$<25 \%$ & $29(85)$ & $36(80)$ & \\
\hline$\geqslant 25 \%$ & $5(15)$ & $9(20)$ & \\
\hline $\begin{array}{l}\text { Severity of stenosis post } \\
\text { TLR }\end{array}$ & & & NS \\
\hline$<25 \%$ & $23(68)$ & $26(58)$ & \\
\hline$\geqslant 25 \%$ & $11(32)$ & $19(42)$ & \\
\hline Length of stenosis & & & NS \\
\hline$<13 \mathrm{~mm}$ & $16(59)$ & $23(60)$ & \\
\hline$\geqslant 13 \mathrm{~mm}$ & $11(41)$ & $15(40$ & \\
\hline RLD initial stent & & & NS \\
\hline$<2.4 \mathrm{~mm}$ & $25(73)$ & $27(60)$ & \\
\hline$\geqslant 2.4 \mathrm{~mm}$ & $9(27)$ & $18(40)$ & \\
\hline $\begin{array}{l}\text { Inflation pressure initial } \\
\text { stent }\end{array}$ & & & NS \\
\hline$<12$ atm & $4(12)$ & $7(16)$ & \\
\hline$\geqslant 12 \mathrm{~atm}$ & $30(88)$ & $38(84)$ & \\
\hline
\end{tabular}

Values are $\mathrm{n}$ or $\mathrm{n}(\%)$.

The residual restenosis rate after follow up was significantly greater than after initial stent placement $\quad(23.3 \quad(8) \% \quad v \quad 17.5 \quad(7) \%$, $\mathrm{p}<0.001)$. At follow up, the overall second in-stent restenosis rate was $57 \%(n=45)$, resulting in a smaller late loss compared with target lesion revascularisation $(0.74(0.7) \mathrm{mm}$ $v 1.52(0.5) \mathrm{mm}, \mathrm{p}<0.05)$.

There was a striking difference in second in-stent restenosis in terms of the strategy for target lesion revascularisation. With excimer laser angioplasty the second in-stent restenosis rate was $78 \%$, significantly higher than with conventional procedures like PTCA $(49 \%)$ or stent deployment $(47 \%) \quad(p<0.05)$. Stent implantation achieved the largest acute gain$1.43(0.4) \mathrm{mm}$, compared with $1.3(0.3) \mathrm{mm}$ with excimer laser angioplasty and 1.1 $(0.2) \mathrm{mm}$ with balloon dilatation $(\mathrm{p}<0.05)$. 
However, there was a greater late loss of efficacy with stent implantation $(0.93$ $(0.4) \mathrm{mm})$ and PTCA $(0.95(0.4) \mathrm{mm})$ than with excimer laser angioplasty $(0.6(0.3) \mathrm{mm})$ $(\mathrm{p}<0.05)$. Overall, the calculated net gain revealed an angiographic benefit of PTCA $(0.5$ $(0.3) \mathrm{mm})$ and stent implantation $(0.5$ $(0.2) \mathrm{mm}$ ) for treatment of in-stent restenosis in comparison with laser angioplasty (0.3 $(0.2) \mathrm{mm}$ ), although this difference did not reach significance.

The luminal dimensions at baseline, before and after stent procedures, and at follow up are listed in tables 3 and 4 . Figure 1 shows the initial, the post-target lesion revascularisation, and the follow up values for minimum lumen diameter.

Twenty five patients with symptomatic restenosis later received a second target lesion revascularisation, whereas 20 did not need further revascularisation.

As others have done in larger vessels, we used several different types of stent in our patients. Most were given slotted or multicellular stents, the most common types of implanted stent in other series. Univariate analysis did not reveal any difference in second in-stent restenosis according to stent design.

PREDICTORS OF IN-STENT RESTENOSIS

To determine whether different clinical, angiographic, or procedural factors convey an increased risk of second in-stent restenosis, we performed per patient and per lesion analyses. The strategy used for target lesion revascularisation of in-stent restenosis was the only independent risk factor for second in-stent restenosis. Neither clinical (for example, diabetes mellitus) nor procedural (balloon to artery ratio) or angiographic factors (lesion length, reference lumen diameter) were associated with an increase in restenosis rate (table 5).

\section{Discussion}

Coronary stent placement has been shown to improve the clinical outcome and reduce angiographic restenosis rate and the need for further target lesion revascularisation in patients with coronary artery disease. ${ }^{12}$ The superiority of coronary stent placement over conventional balloon angioplasty has resulted in its widespread use as the approach of choice for revascularisation of coronary atherosclerosis. However, it should be emphasised that the beneficial results of coronary stenting were assessed in patients with selected lesions in the larger coronary arteries. ${ }^{12}$ Holmes and colleagues, in their updated expert consensus document, state that although stenting of smaller vessels is safe there is no improvement in long term outcome over PTCA. ${ }^{8}$ Despite these concerns, recently published studies have indicated that the clinical and angiographic results of stent placement in the smaller coronary arteries are superior to balloon angioplasty, and that there is no increase in acute stent thrombosis. The potentially high restenosis rate was attributed to several additional risk factors. ${ }^{11} 12$ These findings were previously confirmed by Akiyama and colleagues, who demonstrated the high success rate and the low incidence of stent thrombosis in patients with stent deployment in small coronary arteries (reference lumen diameter $\leqslant 3 \mathrm{~mm}$ ). However, there was a significant increase in restenosis rate in these small arteries, resulting in a less favourable clinical outcome than in patients with large vessel disease (reference lumen diameter $\geqslant 3 \mathrm{~mm}$ ). ${ }^{13}$ Although all these studies have confirmed the feasibility and the low incidence of abrupt closure when stents are used in the smaller coronary arteries, the major limitation of stent deployment is definitely in-stent restenosis. Treatment of this complication may well become one of the main indications in interventional cardiology as the popularity of stenting increases, irrespective of vessel size.

Several investigators using different types of device have successfully treated in-stent restenosis. Although safety and feasibility could be demonstrated, long term results varied with the morphology of the restenosis, the severity of the stenosis before intervention, and the treatment device. Currently available data on the treatment of in-stent restenosis are primarily focused on larger sized vessels. ${ }^{16-22} 25-28$

To the best of our knowledge, this is the first study showing the feasibility and safety of treatment of in-stent restenosis in small coronary arteries or determining predictors of second in-stent restenoses in such patients. Our results show that treatment of in-stent restenosis is feasible and safe, with a high primary success rate accompanied by a comparably favourable clinical outcome during follow up. The presence of severe angina (CCS class IIIIV) was significantly reduced $(33 \%$ v $22 \%$, $\mathrm{p}=0.02$ ) with respect to the entire follow up period (12.6 (2.5) months), resulting in an excellent event free survival. This is in agreement with Reimers and colleagues, who found the rate of major cardiac events to be $20 \%$ at 27.4 (14.7) months in larger coronary arteries. $^{21}$ In our cohort, one non-Q wave infarction caused by acute stent thrombosis occurred, and another patient experienced asymptomatic stent thrombosis within two months.

The purpose of our study was to evaluate the clinical and angiographic outcome after target lesion revascularisation in patients with instent restenosis in small coronary arteries. The reference lumen diameter was $\leqslant 2.85 \mathrm{~mm}$, with an average of $2.17(0.4) \mathrm{mm}$. The mean minimum lumen diameter was $0.58(0.4) \mathrm{mm}$, resulting in a diameter stenosis of 73 (15)\% before target lesion revascularisation. Procedural success was achieved in all patients independent of the strategy for target lesion revascularisation. Although the second in-stent restenosis rate of our patients was $57 \%$, this result compares relatively favourably with the restenosis rate after different treatments for in-stent restenosis in the large coronary arteries. ${ }^{27}$ Eltchaninoff and colleagues recently found an angiographic restenosis rate of $54 \%$ after percutaneous transluminal coronary angioplasty of in-stent restenosis in larger coronary arteries (reference lumen diameter 2.95 
(0.47) mm). Recurrent in-stent restenosis was even higher in patients with diffuse restenosis, at $63 \%, v 31 \%$ when focal stenosis was present. In contrast to the series of Eltchaninoff and colleagues, Bauters and associates found a very low restenosis rate after repeat balloon angioplasty for in-stent restenosis in patients with large coronary artery stents. ${ }^{22}$ However, there was an increased incidence of second in-stent restenoses $(42 \%)$ in patients with diffuse restenosis. In the present study we were unable to show that in-stent restenosis was related to stenosis morphology. Thus although there was a slightly increased rate of restenosis in diffuse as opposed to focal stenosis, this did not reach significance. The relatively small number of patients with diffuse in-stent restenosis might be responsible for the lack of statistical power. Another explanation could be that, irrespective of the lesion morphology, small vessels are more likely to be affected by in-stent restenosis than larger ones, and hence more likely to be subject to additional risk factors. Elezi and colleagues have shown that vessel size is an independent risk factor for clinical and angiographic outcome, and the restenosis rate in patients with primary lesions will be increased by the presence of complex lesions or diabetes mellitus. ${ }^{12}$ One third of our patients had diabetes mellitus and complex lesions were present in more than $95 \%$ of all treated patients.

In accordance with recent publications, we used a visually estimated residual stenosis of $<30 \%$ as a surrogate marker for successful stent implantation. ${ }^{712}$ This might be one reason for the relatively high rate of residual stenosis. The extent to which this influenced the restenosis rate after target lesion revascularisation remains unclear. Savage and colleagues and Akiyama and associates performed stent implantations in smaller vessels $(<3 \mathrm{~mm}$ reference diameter) with different residual stenosis postprocedurally (17 (11)\% $\quad v \quad-2.6$ $(14.9) \%)$; however, the restenosis rate during follow up was equivalent. ${ }^{11}{ }^{13}$ Moreover, recent data indicate that the degree of residual diameter stenosis after stent implantation may not necessarily correlate with angiographic outcome at follow up. For example Bauters and colleagues showed that a low residual stenosis rate after stent placement correlated inversely with late lumen loss. ${ }^{29}$

We found a significant difference in acute gain in terms of the strategy used for target lesion revascularisation. Restenting and excimer laser angioplasty led to a further stent expansion compared with balloon angioplasty alone, even in small stented vessel segments. This mechanism has been described in larger coronary arteries and reflects the different pattern of lumen enlargement obtained by different revascularisation methods. ${ }^{725}$ This increase in acute gain is then compensated for by a greater late loss.

In contrast to others, we found no evidence that excimer laser angioplasty was superior to other methods for target lesion revascularisation of in-stent restenosis in the small coronary arteries. $^{25}{ }^{30}$ The extent of late loss after target lesion revascularisation was considerable and reflects the vessel wall damage caused by this procedure. This might be the reason for a second restenosis rate of $78 \%$. Whether debulking devices like rotational atherectomy or directional coronary atherectomy offer potential advantages for the treatment of in-stent restenosis in small coronary arteries has to be assessed. Preliminary beneficial results are available only for larger vessels. ${ }^{26}$

Conventional balloon angioplasty showed a modest reduction in late loss compared with PTCA followed by stent deployment or excimer laser angioplasty $(0.6 \mathrm{~mm} v 0.9 \mathrm{~mm} v$ $0.9 \mathrm{~mm}, \mathrm{p}<0.05)$, although restenosis rate was slightly higher than in patients with additional stent implantation (NS). The efficacy of this strategy for target lesion revascularisation in terms of early clinical results and complication rate in our series is comparable with the results that have been obtained in large vessels. $^{21} 28$ Balloon angioplasty followed by stent implantation appears to offer a promising approach for target lesion revascularisation of in-stent restenosis. Because in the present study stent implantation was used following complications after balloon dilatation, further investigation of restenting as an elective target lesion revascularisation procedure is necessary. However, on the basis of our results, it appears that conventional percutaneous transluminal coronary angioplasty for in-stent restenosis represents a safe procedure with an acceptable long term angiographic and clinical outcome, which can be successfully performed in small coronary arteries.

\section{LIMITATIONS OF THE STUDY}

The study, though prospective, was nonrandomised and did not exclude the use of any specific strategy. Thus at the discretion of the operator, excimer laser angioplasty, restenting, and balloon angioplasty alone were all used. This reflects the vexing problem of the best management of in-stent restenosis in interventional cardiology, as all available treatment procedures - atheroablative, debulking, or dilatation techniques - are under current debate. Although the purpose of this study was to evaluate the overall angiographic restenosis rate after successful target lesion revascularisation in clinical routine, there was a significant difference in terms of the target lesion revascularisation procedure. The small number of patients in each subgroup and the nonrandomised study setting have to be borne in mind before any possibly misleading conclusions are drawn. However, our approach reflects the routine angiographic and clinical situation for interventional cardiologists in treating patients with in-stent restenosis. Hence there is a need for randomised trials to overcome these hazards.

\section{CONCLUSIONS}

Target lesion revascularisation for in-stent restenosis in patients with small coronary arteries is feasible and safe, with a second in-stent restenosis rate comparable with those in series examining the treatment of in-stent restenosis 
in the large coronary arteries. In our patient cohort, the strategy for treatment of in-stent restenosis influenced the subsequent angiographic restenosis rate, and atheroablation significantly increased in-stent restenosis. The use of excimer laser angioplasty for treatment of in-stent restenosis in small coronary arteries is therefore open to question.

1 Serruys PW, De Jaegere P, Kiemenej F, et al, for the Benestent Study Group. A comparison of balloon-expandable stent implantation with balloon angioplasty in patients
with coronary artery disease. N Engl f Med 1994;331:48995.

2 Fischman DL, Leon MB, Baim DS, et al, for the Stent Restenosis Study Investigators. A randomized comparison of coronary-stent placement and balloon angioplasty in the treatment of coronary artery disease. $N$ Engl $f \mathrm{Med}$ 1994;331:496-501.

3 Hirshfeld JW, Schwartz JS, Jugo R, et al. Restenosis after coronary angioplasty: a multivariate statistical model to coronary angioplasty: a multivariate statistical model to relate lesion and procedural

4 Foley DP, Melkert R, Serruys PW, et al. Influence of coronary vessel size on renarrowing process and late angiographic outcome after successful balloon angioplasty. Circulation 1994;90:1239-51.

5 Keane D, Azar AJ, de Jaegere P, et al. Clinical and angiographic outcome of elective stent implantation in small coronary vessels: an analysis of the BENESTENT trial. Semin Intervent Cardiol 1996;1:255-62.

6 Akiyama T, Goldberg SL, Di Mario C, et al. Stenting small vessels. Eur Heart f 1997; 18(suppl):381.

7 Kastrati A, Schömig A, Elezi S, et al. Predictive factors of restenosis after coronary stent placement. $7 \mathrm{Am}$ Coll Cardiol 1997;30:1428-36.

8 Holmes DR, Hirshfeld JW, Faxon D, et al. ACC Expert Consensus Document on Coronary Artery Stents. Document of the American College of Cardiology. $7 \mathrm{Am} \mathrm{Coll}$ ment of the American Col

9 Nath FC, Muller DW, Ellis SG, et al. Thrombosis of a flexible coil coronary stent: frequency, predictors and clinical ible coil coronary stent: frequency, predictors
outcome. F Am Coll Cardiol 1993;21:622-7.

10 Sutton JM, Ellis SG, Roubin GS, et al. Topol EJ for the Giantourco-Roubin Intracoronary Stent Investigator Group. Major clinical events after coronary stenting. Circulation 1994;89:11126-37.

11 Savage MP, Fischman DL, Rake R, et al. Efficacy of coronary stenting versus balloon angioplasty in small coronary arteries: Stent Restenosis Study (STRESS) Investigators. $f$ Am Coll Cardiol 1998;31:307-11.

12 Elezi S, Kastrati A, Neumann FJ, et al. Vessel size and longterm outcome after coronary stent placement. Circulation 1998;98:1875-80.

13 Akiyama T, Moussa I, Reimers B, et al. Angiographic and clinical outcome following coronary stenting of small vessels: a comparison with coronary stenting of larger vesvess. 7 Am Coll Cardiol 1998;32:1610-18.
14 Gordon P, Gibson M, Cohen D, et al. Mechanisms of restenosis and redilatation within coronary stentsquantitative angiogra

15 Baim DS, Levine MJ, Leon MB, et al, for the US Palmaz-Schatz Investigators. Management of restenosis within the Palmaz-Schatz coronary stent (the US multicenter experience). The US Palmaz-Schatz Stent Investigators. Am f Cardiol 1993;71:364-6.

16 Macander PJ, Roubin GS, Agrawal SK, et al. Balloon angioplasty for treatment of in-stent restenosis: feasibility, safety, and efficacy. Cathet Cardiovasc Diagn 1994;32:125-31.

17 Hoffmann R, Mintz GS, Dussaillant GR, et al. Patterns and mechanisms of in-stent restenosis. A serial intravascular mechanisms of in-stent restenosis. A serial in

18 Mehran R, Mintz GS, Popma JJ, et al. Mechanisms and results of balloon angioplasty for the treatment of in-stent restenosis. Am F Cardiol 1996;78:618-22.

19 Topaz O, Vetrovec GW. The stenotic stent: mechanisms and revascularization options. Cathet Cardiovasc Diagn 1996;37: 293-9.

20 Vahdat B, Bonan R, Paiement P, et al. Management of coronary in-stent restenosis by balloon angioplasty. Eur Heart 7 1997;18:498.

21 Reimers B, Moussa I, Akiyama T, et al. Long-term clinical follow-up after successful repeat percutaneous intervention for stent restenosis. $\mathcal{F}$ Am Coll Cardiol 1997;30:186-92.

22 Bauters C, Banos JL, Van Belle E, et al. Six-month angiographic outcome after successful repeat percutaneous intervention for in-stent restenosis. Circulation 1998;97: $318-21$.

23 Kumra T, Tamura T, Yokoi H, et al. Long-term clinical and angiographic follow-up after placement of Palmaz-Schatz coronary stent: a single center experience. F Intervent Cardiol 1994;7:129-39.

24 Ryan TJ, Faxon DP, Gunnar RM, et al. Guidelines for percutaneous transluminal coronary angioplasty: a report of the American College of Cardiology/American Heart Association Task Force on assessment of diagnostic and therapeutic cardiovascular procedures. Circulation 1988;78: 486-502.

25 Mehran R, Mintz G, Satler LF, et al. Treatment of in-stent restenosis with excimer laser coronary angioplasty: mechanisms and results compared with PTCA alone. Circulation 1997;96:2183-9.

26 Sharma SK, Duvvuri S, Dangas G, et al. Rotational atherectomy for in-stent restenosis: acute and long-term results of tomy for in-stent restenosis: acute and long-term results of
the first 100 cases. $\mathcal{F}$ Am Coll Cardiol 1998;32:1358-65.

27 Dauerman HL, Baim DS, Cutlip DE, et al. Mechanical debulking versus balloon angioplasty for the treatment of diffuse in-stent restenosis. Am F Cardiol 1998;82:277-84.

28 Eltchaninoff $\mathrm{H}$, Koning $\mathrm{R}$, Tron $\mathrm{C}$, et al. Balloon angioplasty for the treatment of coronary in-stent restenosis: immediately results and 6-month angiographic
recurrent restenosis rate. $\mathcal{F}$ Am Coll Cardiol 1998;32:980-4.

29 Bauters C, Hubert E, Prat A, et al. Predictors of restenosis after coron

30 Hamm CW, Seabra-Gomes R, Bonnier J, et al, on the behalf of the LARS Study group. Laser angioplasty of within-stent restenosis-results of the LARS surveillance study. Eur Heart $\mathcal{F}$ 1997; 18:497. 